\title{
References of Part II
}

Bard, E., and M. Frank. Climate change and solar variability: What's new under the sun? Earth and Planetary Science Letters, 248, 1-14, 2006. DOI:10.1016/j.epsl.2006.06.016.

Baumgaertner, A. J. G., P. Jöckel, and C. Brühl. Energetic particle precipitation in ECHAM5/MESSy1 - Part 1: Downward transport of upper atmospheric $\mathrm{NO}_{x}$ produced by low energy electrons. Atmospheric Chemistry \&6 Physics, 9, 2729$2740,2009$.

Bazilevskaya, G. A., I. G. Usoskin, E. O. Flückiger, R. G. Harrison, L. Desorgher, et al. Cosmic Ray Induced Ion Production in the Atmosphere. Space Science Reviews, 137, 149-173, 2008. DOI:10.1007/s11214-008-9339-y.

Beer, J., K. McCracken, and R. von Steiger. Cosmogenic Radionuclides. Springer Verlag, Berlin, 2012.

Berger, A., M. F. Loutre, and M. Crucifix. The Earth's Climate in the Next Hundred Thousand years (100 kyr). Surveys in Geophysics, 24, 117-138, 2003.

Berger, A. L. Long-Term Variations of Daily Insolation and Quaternary Climatic Changes. Journal of Atmospheric Sciences, 35, 2362-2367, 1978. DOI:10.1175/1520-0469(1978)035¡2362:LTVODI ¿2.0.CO;2.

Clette, F., L. Svalgaard, J. M. Vaquero, and E. W. Cliver. Revisiting the Sunspot Number. A 400-Year Perspective on the Solar Cycle. Space Science Reviews, 186, 35-103, 2014. DOI:10.1007/s11214-014-0074-2.

Clilverd, M. A., E. Clarke, T. Ulich, J. Linthe, and H. Rishbeth. Reconstructing the long-term aa index. Journal of Geophysical Research, 110, 7205, 2005. DOI:10.1029/2004JA010762.

Dasi-Espuig, M., J. Jiang, N. A. Krivova, and S. K. Solanki. Modelling total solar irradiance since 1878 from simulated magnetograms. Astronomy and Astrophysics, 570, A23, 2014. DOI:10.1051/0004-6361/201424290.

DeLand, M. T., and R. P. Cebula. Creation of a composite solar ultraviolet irradiance data set. Journal of Geophysical Research (Space Physics), 113, 11103, 2008. DOI:10.1029/2008JA013401.

Desorgher, L., E. O. Flückiger, M. Gurtner, M. R. Moser, and R. Bütikofer. Atmocosmics: a Geant 4 Code for Computing the Interaction of Cosmic Rays with the Earth's Atmosphere. International Journal of Modern Physics A, 20, 6802-6804, 2005. DOI:10.1142/S0217751X05030132. 
Dorman, L. I., ed. Cosmic Rays in the Earth's Atmosphere and Underground, vol. 303 of Astrophysics and Space Science Library, 2004.

Eddy, J. A. The Maunder Minimum. Science, 192, 1189-1202, 1976. DOI:10.1126/science.192.4245.1189.

Ermolli, I., K. Matthes, T. Dudok de Wit, N. A. Krivova, K. Tourpali, et al. Recent variability of the solar spectral irradiance and its impact on climate modelling. Atmospheric Chemistry and Physics, 13, 3945-3977, 2013. DOI:10.5194/acp13-3945-2013, 1303.5577.

Forbush, S. E. On the Effects in Cosmic-Ray Intensity Observed During the Recent Magnetic Storm. Physical Review, 51, 1108-1109, 1937. DOI:10.1103/PhysRev.51.1108.3.

Funke, B., M. López-Puertas, L. Holt, C. E. Randall, G. P. Stiller, and T. von Clarmann. Hemispheric distributions and interannual variability of NOy produced by energetic particle precipitation in 2002-2012. Journal of Geophysical Research: Atmospheres, 119(23), 2014. DOI:10.1002/2014JD022423, http: //dx.doi.org/10.1002/2014JD022423.

Haberreiter, M., W. Schmutz, and Kosovichev, A. G. Solving the discrepancy between the seismic and photospheric solar radius. Astrophysical Journal, 675, L53-L56, 2008.

Harder, J. W., J. M. Fontenla, P. Pilewskie, E. C. Richard, and T. N. Woods. Trends in solar spectral irradiance variability in the visible and infrared. Geophysical Research Letters, 36, 2009. DOI:10.1029/2008GL036797.

Jackman, C. H., D. R. Marsh, F. M. Vitt, R. R. Garcia, E. L. Fleming, et al. Shortand medium-term atmospheric constituent effects of very large solar proton events. Atmospheric Chemistry 8 Physics, 8, 765-785, 2008.

Jackman, C. H., D. R. Marsh, F. M. Vitt, R. R. Garcia, C. E. Randall, E. L. Fleming, and S. M. Frith. Long-term middle atmospheric influence of very large solar proton events. Journal of Geophysical Research (Atmospheres), 114, D11304, 2009. DOI:10.1029/2008JD011415.

Judge, P. G., G. W. Lockwood, R. R. Radick, G. W. Henry, A. I. Shapiro, W. Schmutz, and C. Lindsey. Confronting a solar irradiance reconstruction with solar and stellar data. Astronomy and Astrophysics, 544, A88, 2012. DOI:10.1051/0004-6361/201218903.

Kopp, G., and J. L. Lean. A new, lower value of total solar irradiance: Evidence and climate significance. Geophysical Research Letters, 38, 1706, 2011. DOI:10.1029/2010GL045777. 
Korte, M., C. Constable, F. Donadini, and R. Holme. Reconstructing the Holocene geomagnetic field. Earth and Planetary Science Letters, 312, 497-505, 2011. DOI:10.1016/j.epsl.2011.10.031.

Krivova, N. A., L. E. A. Vieira, and S. K. Solanki. Reconstruction of solar spectral irradiance since the Maunder minimum. Journal of Geophysical Research (Space Physics), 115(A12), 2010. http://dx.doi.org/10.1029/2010JA015431.

Lockwood, M., and M. J. Owens. Centennial changes in the heliospheric magnetic field and open solar flux: The consensus view from geomagnetic data and cosmogenic isotopes and its implications. Journal of Geophysical Research (Space Physics), 116, 4109, 2011. DOI:10.1029/2010JA016220.

Marsh, D. R., R. R. Garcia, D. E. Kinnison, B. A. Boville, F. Sassi, S. C. Solomon, and K. Matthes. Modeling the whole atmosphere response to solar cycle changes in radiative and geomagnetic forcing. Journal of Geophysical Research (Atmospheres), 112, 23306, 2007. DOI:10.1029/2006JD008306.

Menvielle, M., and A. Berthelier. The K-derived planetary indices - Description and availability. Reviews of Geophysics, 29, 415-432, 1991.

Petit, J. R., J. Jouzel, D. Raynaud, N. I. Barkov, J.-M. Barnola, et al. Climate and atmospheric history of the past 420,000 years from the Vostok ice core, Antarctica. Nature, 399, 429-436, 1999. DOI:10.1038/20859.

Porter, H. S., C. H. Jackman, and A. E. S. Green. Efficiencies for production of atomic nitrogen and oxygen by relativistic proton impact in air. Journal of Chemical Physics, 65, 154-167, 1976. DOI:10.1063/1.432812.

Potgieter, M. Solar Modulation of Cosmic Rays. Living Reviews in Solar Physics, 10, 3, 2013. DOI:10.12942/lrsp-2013-3, 1306.4421.

Quack, M., M.-B. Kallenrode, M. von Koenig, K. Kuenzi, J. Burrows, B. Heber, and E. Wolff. Ground level events and consequences for stratospheric chemistry. International Cosmic Ray Conference, 10, 4023, 2001.

Rodger, C. J., M. A. Clilverd, J. C. Green, and M. M. Lam. Use of POES SEM-2 observations to examine radiation belt dynamics and energetic electron precipitation into the atmosphere. Journal of Geophysical Research (Space Physics), 115, 4202, 2010. DOI:10.1029/2008JA014023.

Schmidt, G. A., J. H. Jungclaus, C. M. Ammann, E. Bard, P. Braconnot, et al. Climate forcing reconstructions for use in PMIP simulations of the last millennium (v1.1). Geoscientific Model Development Discussions, 3(3), 1549-1586, 2010. DOI:10.5194/gmdd-3-1549-2010, http://www . geosci-model-dev-discuss . net/3/1549/2010/. 
Schmutz, W., A. Fehlmann, W. Finsterle, G. Kopp, and G. Thuillier. Total solar irradiance measurements with PREMOS/PICARD. In American Institute of Physics Conference Series, vol. 1531 of American Institute of Physics Conference Series, 624-627, 2013. DOI:10.1063/1.4804847.

Schrijver, C. J., W. C. Livingston, T. N. Woods, and R. A. Mewaldt. The minimal solar activity in 2008-2009 and its implications for long-term climate modeling. Geophysical Research Letters, 38, L06701, 2011. DOI:10.1029/2011GL046658.

Seppälä, A., K. Matthes, C. E. Randall, and I. A. Mironova. What is the solar influence on climate? Overview of activities during CAWSES-II. Progress in Earth and Planetary Science, 1, 24, 2014. DOI:10.1186/s40645-014-0024-3.

Shapiro, A. I., W. Schmutz, E. Rozanov, M. Schoell, M. Haberreiter, A. V. Shapiro, and S. Nyeki. A new approach to the long-term reconstruction of the solar irradiance leads to large historical solar forcing. Astronomy $\&$ Astrophysics, 529, A67, 2011. DOI:10.1051/0004-6361/201016173.

Solanki, S. K., N. A. Krivova, and J. D. Haigh. Solar Irradiance Variability and Climate. Annual Review of Astronomy and Astrophysics, 51, 311-351, 2013. DOI:10.1146/annurev-astro-082812-141007, 1306.2770.

Stap, L. B., R. S. W. van de Wal, B. de Boer, R. Bintanja, and L. J. Lourens. Interaction of ice sheets and climate during the past 800000 years. Climate of the Past, 10, 2135-2152, 2014. DOI:10.5194/cp-10-2135-2014.

Steinhilber, F., J. A. Abreu, J. Beer, I. Brunner, M. Christl, et al. 9,400 years of cosmic radiation and solar activity from ice cores and tree rings. Proceedings of the National Academy of Sciences, 109(16), 5967-5971, 2012. DOI:10.1073/pnas.1118965109, http://www.pnas.org/content/109/ 16/5967.full.pdf+html, http://www.pnas.org/content/109/16/5967. abstract.

Steinhilber, F., J. Beer, and C. Fröhlich. Total solar irradiance during the Holocene. Geophysical Research Letters, 36, 2009. DOI:10.1029/2009GL040142.

Svalgaard, L., and E. W. Cliver. Long-term geomagnetic indices and their use in inferring solar wind parameters in the past. Adv. Space Research, 40, 1112-1120, 2007. DOI:10.1016/j.asr.2007.06.066.

Tanskanen, E. I. A comprehensive high-throughput analysis of substorms observed by IMAGE magnetometer network: Years 1993-2003 examined. Journal of Geophysical Research (Space Physics), 114, 5204, 2009. DOI:10.1029/2008JA013682.

Trenberth, K. E., J. T. Fasullo, and J. Kiehl. Earth's Global Energy Budget. Bulletin of the American Meteorological Society, 90, 311-324, 2009. DOI:10.1175/2008BAMS2634.1. 
Usoskin, I. G., G. Hulot, Y. Gallet, R. Roth, A. Licht, F. Joos, G. A. Kovaltsov, E. Thébault, and A. Khokhlov. Evidence for distinct modes of solar activity. Astron. Astrophys., 562, L10, 2014. DOI:10.1051/0004-6361/201423391, 1402.4720 .

Usoskin, I. G., and G. A. Kovaltsov. Cosmic ray induced ionization in the atmosphere: Full modeling and practical applications. Journal of Geophysical Research (Atmospheres), 111, 21206, 2006. DOI:10.1029/2006JD007150.

Usoskin, I. G., G. A. Kovaltsov, and I. A. Mironova. Cosmic ray induced ionization model CRAC:CRII: An extension to the upper atmosphere. Journal of Geophysical Research (Atmospheres), 115, 10302, 2010. DOI:10.1029/2009JD013142.

Usoskin, I. G., S. K. Solanki, and G. A. Kovaltsov. Grand minima and maxima of solar activity: new observational constraints. Astron. Astrophys., 471, 301-309, 2007. DOI:10.1051/0004-6361:20077704, arXiv:0706.0385.

Vieira, L. E. A., S. K. Solanki, N. A. Krivova, and I. Usoskin. Evolution of the solar irradiance during the Holocene. Astronomy and Astrophysics, 531, A6, 2011. DOI:10.1051/0004-6361/201015843, 1103.4958.

Yeo, K. L., N. A. Krivova, and S. K. Solanki. Solar Cycle Variation in Solar Irradiance. Space Science Reviews, 186, 137-167, 2014. DOI:10.1007/s11214014-0061-7. 
